\title{
Training early childcare providers in evidence-based nutrition strategies can help improve nutrition policies and practices of early childcare centres serving racially and ethnically diverse children from low-income families
}

\author{
T Lucas Hollar ${ }^{1, *}$, Nicole Cook ${ }^{1}$, Ruby Natale ${ }^{2}$, David Quinn ${ }^{3}$, Teina Phillips ${ }^{4}$ and \\ Michael Delucca ${ }^{4}$ \\ ${ }^{1}$ Nova Southeastern University, College of Osteopathic Medicine, Master of Public Health, Program, 3200 South \\ University Drive, Fort Lauderdale, FL 33328, USA: ${ }^{2}$ University of Miami, Miller School of Medicine, Miami, FL, USA: \\ ${ }^{3}$ Nova Southeastern University, Area Health Education Center, Fort Lauderdale, FL, USA: ${ }^{4}$ Broward Regional Health \\ Planning Council, Hollywood, FL, USA
}

Submitted 7 March 2017: Final revision received 22 September 2017: Accepted 18 October 2017: First published online 13 December 2017

\begin{abstract}
Objective: We evaluated the extent to which providing training and technical assistance to early childcare centre (ECC) directors, faculty and staff in the implementation of evidence-based nutrition strategies improved the nutrition contexts, policies and practices of ECC serving racially and ethnically diverse, lowincome children in Broward County, Florida, USA. The nutrition strategies targeted snack and beverage policies and practices, consistent with Caring for Our Children National Standards.

Design: We used the nutrition observation and document review portions of the Environment and Policy Assessment and Observation (EPAO) instrument to observe ECC as part of a one-group pre-test/post-test evaluation design.

Setting: ECC located within areas of high rates of poverty, diabetes, minority representation and unhealthy food index in Broward County, Florida, USA.

Subjects: Eighteen ECC enrolled, mean 112.9 (SD 53.4) children aged 2-5 years; 12.3 (SD 7.2) staff members; and 10.2 (SD 4.6) children per staff member at each centre. Results: We found significant improvements in centres' overall nutrition contexts, as measured by total EPAO nutrition scores $(P=0.01)$. ECC made specific significant gains within written nutrition policies $(P=0.03)$ and nutrition training and education $(P=0 \cdot 01)$.

Conclusions: Our findings support training ECC directors, faculty and staff in evidence-based nutrition strategies to improve the nutrition policies and practices of ECC serving racially and ethnically diverse children from low-income families. The intervention resulted in improvements in some nutrition policies and practices, but not others. There remains a need to further develop the evaluation base involving the effectiveness of policy and practice interventions within ECC serving children in high-need areas.
\end{abstract}

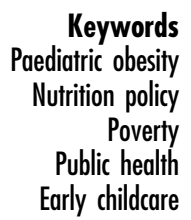

Disparities in obesity persist in children of pre-school age across racial, ethnic and income groups ${ }^{(1,2)}$, despite both claims of an overall decline in the percentage of children under 5 years in the USA who are obese ${ }^{(1)}$ and opposing claims of there being no evidence of declines in obesity in any age group ${ }^{(3)}$. For children between the ages of 2 and 5 years, $11.3 \%$ of non-Hispanic black, $16.7 \%$ of Hispanic and $3.5 \%$ of non-Hispanic white are obese ${ }^{(1)}$. Across income levels, the percentage of children aged 2-4 years who are obese is highest among children living in families at or below the poverty level, followed by children living in low-income families ${ }^{(4)}$. These disparities are troubling because childhood obesity corresponds with social, psychological and pathophysiological health effects ${ }^{(5,6)}$. Additionally, the early childhood experiences and conditions of 2-5-year-olds influence children's weight status later in childhood $^{(7)}$, and childhood obesity is associated with increased morbidity and mortality in adulthood ${ }^{(5,8,9)}$. This is particularly problematic among racial and ethnic groups disparately affected by obesity-related chronic diseases ${ }^{(6,8)}$.

Due to the amount of time large numbers of children spend in early childcare centres (ECC), the nutritional 
intake of children within ECC and the potential benefits of early-targeted obesity prevention interventions, ECC are valuable public health arenas for developing healthy behaviours and weight status among young children $^{(5,7,8,10-17)}$. On average, children between the ages of 3 and 5 years, who are enrolled in ECC and whose mothers are employed, spend $33 \mathrm{~h} /$ week in ECC-based care, and those whose mothers are not employed spend an average of $25 \mathrm{~h} /$ week in ECC-based care ${ }^{(18)}$. Sixty-one per cent of children between the ages of 3 and 5 years, who are not enrolled in kindergarten, are cared for in $\mathrm{ECC}^{(19)}$. These children consume one-half to two-thirds of their energy intake within $\mathrm{ECC}^{(20)}$ and research suggests that most children's dietary intake in ECC settings do not meet the recommendations of the Dietary Guidelines for Americans ${ }^{(12,21)}$. Further, evidence suggests that children's eating behaviours and attitudes are influenced by ECC staff behaviours and ECC food service, such as menu planning, food preparation and the style of serving food ${ }^{(8,10,13,14,22)}$. This is significant since children's dietary behaviours have been found to be associated with childhood obesity, particularly the poor management of portion sizes ${ }^{(23)}$, the consumption of sugar-sweetened beverages ${ }^{(23-26)}$ and the consumption of energy-dense foods ${ }^{(23,24,27-29)}$.

There is a need for more investigation into the implementation and effects of environmental and policy-based obesity prevention initiatives in settings other than schools ${ }^{(14,30,31)}$. This includes the need for further development of the literature base on such interventions in $\mathrm{ECC}^{(12)}$. There is a particular need for studies that focus on policy-level interventions that incorporate evidence-based guidelines and practices ${ }^{(8)}$ and that reach minority children in institutional settings, such as $\mathrm{ECC}^{(32)}$. Our study focuses on ECC serving racially and ethnically diverse children located within areas of high rates of poverty, diabetes, minority representation and unhealthy food index (unhealthy retail to healthy retail square footage by population density). We evaluated the extent to which training ECC directors, faculty and staff in the implementation of evidence-based nutrition strategies improved the nutrition policies and practices of ECC serving racially and ethnically diverse, low-income children in Broward County, Florida, USA.

\section{Methods}

\section{Study design}

We conducted a one-group pre-test/post-test evaluation of the nutrition component of a county-wide training programme for ECC directors, faculty and staff, designed to help in the implementation of evidence-based nutrition policies and practices, to determine whether nutrition policies and practices improved in ECC. The intervention lasted 3 months and the evaluation period from baseline to follow-up was 12 months.

\section{Study population}

Our study population consisted of a stratified random sample of eligible ECC in Broward County, Florida. The eligible sampling frame consisted of 144 ECC, and it included all licensed ECC in Broward County that participated in the Broward County Quality Counts programme, a voluntary quality improvement initiative for ECC; the US Department of Agriculture (USDA) Child and Adult Care Food Program (CACFP) in Broward County, a USDA programme providing financial reimbursements for meals served in ECC whose enrolment is at least $25 \%$ low-income; and the Transforming Our Community's Health (TOUCH) collaborative. We drew a stratified random sample to cover TOUCH priority zip codes, secondary zip codes and additional zip codes. The priority and secondary priority zip codes were identified through a geographic information system analysis of zip codes within Broward County that had higher proportions than those of the county for diabetes, poverty and population identified as black, and higher scores than that of the county for unhealthy food index. Priority zip codes involved the convergence of all four variables and secondary priority zip codes involved the convergence of at least diabetes and poverty, excluding priority zip codes. Additional zip codes had proportions for these variables at or below those of the county (Table 1).

\section{Intervention}

TOUCH is a collaborative effort among community organizations and coalitions within Broward County, Florida, funded by a Centers for Disease Control and Prevention (CDC) Community Transformation Grant ${ }^{(33,34)}$, to reduce

Table 1 Demographic characteristics of the zip codes in which early childcare centres (ECC) participating in Transforming Our Community's Health were located, Broward County, Florida, USA, 2013-2014*

\begin{tabular}{|c|c|c|c|c|}
\hline Demographics (\%) & $\begin{array}{l}\text { Priority zip codes } \\
\quad\left(n_{\mathrm{ECC}} 10\right)\end{array}$ & $\begin{array}{c}\text { Secondary and additional } \\
\text { zip codes } \\
\left(n_{\mathrm{ECC}} 8\right)\end{array}$ & Broward county & Florida \\
\hline Population under 5 years of age & $7 \cdot 7$ & $5 \cdot 8$ & $5 \cdot 9$ & $5 \cdot 6$ \\
\hline Black or African American & 63.6 & $24 \cdot 3$ & $27 \cdot 2$ & $16 \cdot 0$ \\
\hline White & $28 \cdot 7$ & $65 \cdot 0$ & $63 \cdot 3$ & $76 \cdot 3$ \\
\hline Hispanic & 13.2 & 28.5 & $25 \cdot 8$ & 22.9 \\
\hline $\begin{array}{l}\text { Children under } 5 \text { years living below the } \\
\text { poverty level }\end{array}$ & $42 \cdot 9$ & $19 \cdot 2$ & $21 \cdot 4$ & $26 \cdot 6$ \\
\hline
\end{tabular}

*Demographic characteristics come from US Census Bureau, 2009-2013 5-Year American Community Survey. 
health disparities and to improve the health of Broward County residents ${ }^{(35)}$. TOUCH included a strategy to increase the number of children being cared for in licensed ECC that meet Caring for Our Children (CFOC) National Health and Safety Performance Nutrition Standards ${ }^{(36)}$, a set of national standards presenting evidence-based best practices in nutrition, physical activity and screen time for ECC, authored by the American Academy of Pediatrics, the American Public Health Association, and the National Resource Center for Health and Safety in Child Care and Early Education.

TOUCH implemented a train-the-trainer programme for conducting assessments of, training and providing technical assistance to ECC. TOUCH team members trained Quality Counts Master Teachers (QCMT) on a previously established nutrition and physical activity programme ${ }^{(37)}$ to then train the directors, faculty and/or staff of ECC. The QCMT training involved two all-day sessions, including large group instruction, small breakout sessions and role-playing how to work with barriers. The TOUCH team members leading the trainings consisted of a paediatric psychologist (PhD, PsyD) and a registered dietitian, who is also a licensed dietitian/nutritionist (RD, LDN), with expertise in obesity prevention interventions. The QCMT had master's degrees in education (MEd) or related fields, and they were recruited from the Quality Counts quality improvement initiative for ECC in Broward County, Florida.

In an effort to defray the costs of implementing the programme, TOUCH utilized a tiered approach in which the ECC in most need received technical assistance in addition to a two-hour group training workshop. The first step was to determine centres' levels of need by having ECC complete the Health Environment Rating Scale (HERS) self-assessment tool ${ }^{(38)}$. HERS covers centres' levels of implementation of selected CFOC nutrition and physical activity standards (beverage, snack time, physical activity and screen time standards). TOUCH partners scored the HERS, determined which ECC qualified for Tier 1 or Tier 2 services based on predetermined criteria, and matched the individual centres' areas of weaknesses with corresponding recommendations for improvements. Tier 1 services, for ECC least in need, involved a two-hour group training workshop on how to implement a fourcomponent wellness plan based on the CFOC standards. Tier 2 services, for ECC most in need, involved the twohour group training workshop plus on-site technical assistance provided by the QCMT.

The registered dietitian (licensed dietitian/nutritionist) met with Tier 1 and Tier 2 ECC, and the catering companies that provided the centres' meals and snacks, to assist with menu changes and planning as related to consistency with the CFOC guidelines, the Dietary Guidelines for Americans ${ }^{(39)}$ and the CACFP meal patterns ${ }^{(40)}$. All recommendations were cost neutral to facilitate sustainability. Regardless of tier designation, the registered dietitian (licensed dietitian/nutritionist) visited each ECC two to three times during the first three months of the intervention, depending on each centre's need for services.

The two-hour policy and practice implementation training that both Tier 1 and Tier 2 ECC participated in addressed: (i) Snack Policy: serve fresh vegetables and fresh, frozen-thawed or canned fruit (after draining), avoid high-sugar/high-fat foods, serve whole-grain snacks, include children in preparation of snacks/meals where possible, use non-food incentives or rewards with children, do not withhold food from children as punishment, eliminate choking and allergy risks; and (ii) Beverage Policy: water is readily available throughout the day in all indoor and outdoor areas, $1 \%$ fat or less cow's milk served to 2-5-year-olds, $100 \%$ pasteurized fruit or vegetable juice served once per week, no added sugar or artificial sweeteners to water or flavoured waters, staff as role models - selecting water or other low-calorie and/or nutritious beverages (no soda or diet drinks) while at the centre. Although not the focus of the present evaluation, the training for both Tier 1 and Tier 2 ECC also addressed a Physical Activity Policy and a Screen Time Policy. Infused throughout the training was the importance of ECC personnel serving as healthy role models for the children.

To support the policies, lesson plans were developed that corresponded with the policy topics. The lesson plans consisted of activities the teachers could use for the children in their classroom and were based on 'best practice' principles from our previous published work, including ways to: decrease the consumption of high-fructose and high-fat beverages; decrease the consumption of simplecarbohydrate snacks; increase the consumption of fresh fruits, vegetables and whole grains; reduce screen time; and increase physical activity ${ }^{(37,38,41,42)}$. These lesson plans, intended to help the ECCs align themselves with the CFOC standards, were based on research regarding the effects of obesity prevention programmes in a childcare setting $^{(37,38)}$, as well as the importance of policy-based interventions $^{(41)}$ and the inclusion of teachers as role models ${ }^{(42)}$.

Within two weeks following the workshop, the QCMT contacted the Tier 2 ECC to schedule and deliver the first technical assistance visit. The QCMT visited each Tier 2 ECC each month for the first three months after the twohour workshop. Across three monthly technical assistance visits, the QCMT utilized the evidenced-based lesson plans, described above, from the two-hour training and additional nutrition education materials from an accompanying manual of resources. The manual of resources ${ }^{(43)}$ is a TOUCH team member curated collection of curricular materials from the USDA Food and Nutrition Service ${ }^{(44)}$, the USDA Center for Nutrition Policy and Promotion ${ }^{(45)}$, the Florida Department of Health Child Care Food Program $^{(46)}$, and Share Our Strength's Cooking Matters: No Kid Hungry ${ }^{(47)}$. Based on the centres' specific areas of 
weakness identified through the HERS, the technical assistance targeted centre-based practices likely to help the ECC meet the CFOC standards and to improve the nutrition and/or physical activity of the children. The technical assistance visits also assisted the centres on identifying barriers to implementation of policies and provided solutions.

\section{Data collection instrument}

The Environment and Policy Assessment and Observation (EPAO) tool is a validated observation protocol for assessing the nutrition and physical activity environments of $\operatorname{ECC}^{(48,49)}$. We employed the nutrition component of the EPAO instrument to collect data on nutrition policies and practices within the ECC.

\section{Observations}

Baseline data collection occurred in spring 2013. Followup data collection occurred in spring 2014, after all ECC had received their trainings and after Tier 2 ECC had received their three monthly technical assistance visits. The time period between baseline and follow-up data collection was the same for Tier 1 and Tier 2 ECC. During both data collection periods (spring 2013 and spring 2014), trained EPAO observers visited each of the ECC in the sample. Six of the first ECC visited at baseline, and seven of the first ECC visited at follow-up, were observed by one graduate student and one evaluation team leader to establish inter-rater reliability. Either one graduate student or one evaluation team leader observed the remaining ECC for each wave of observations. Each EPAO observer also had an appropriate-level background check to allow the observer to enter the participating ECC.
Observations began just before breakfast and ended after lunch. Upon arriving at each centre, observers randomly selected a classroom to observe for the entirety of the observation visit. Observers requested to review each centre's policy documents pertaining to any nutrition issues, such as menus, parent newsletters, parent/student handbooks, etc., before concluding the observation. EPAO observations were recorded on paper protocols and the observers or the evaluation coordinator entered individual protocols into a Snap Survey software system via a webbased data entry interface (Snap Surveys, Portsmouth, NH, USA). Once entered, we verified the accuracy of each protocol prior to exporting the resultant data for analysis.

\section{Measures}

Our use of the nutrition components of the EPAO involved the overall EPAO nutrition score and eight nutrition subscales for assessing centres' nutrition contexts (Table 2). The specific nutrition subscales included: written nutrition policy; nutrition training and education; staff nutrition behaviour; nutrition environment; fruits and vegetables; grains, beans and lean meat; high fat/high sugar; and beverage. For our evaluation, we also included a water composite, composed of the access to drinking-water items within the beverage subscale.

\begin{abstract}
Analysis
EPAO data were scored by way of converting recorded observations to assigned values on a three-point scale, ranging from 0 to $2^{(48,50)}$. The scoring for observations can vary across EPAO items. For example, an observation of 0 for number of times high-fat foods are included on a menu could be converted to a score of 2 ; while an observation of 0 for the
\end{abstract}

Table 2 Environment and Policy Assessment and Observation (EPAO) nutrition and nutrition subscale items, Broward County, Florida, USA, 2013-2014

\begin{tabular}{|c|c|}
\hline EPAO nutrition subscale items & Content scored \\
\hline \multicolumn{2}{|c|}{ Nutrition policy, education and modelling } \\
\hline Nutrition policy & $\begin{array}{l}\text { Centre has written policies on nutrition and food service; centre has policies on types of healthier } \\
\text { option foods allowable for holidays and for fundraising }\end{array}$ \\
\hline Nutrition training and education & $\begin{array}{l}\text { Staff spoke with children about healthful foods; staff provided formal nutrition education to } \\
\text { children; centre has documented staff nutrition curriculum; centre has documentation of parent } \\
\text { nutrition education materials }\end{array}$ \\
\hline Staff nutrition behaviour & $\begin{array}{l}\text { Extent to which staff encouraged children to eat more than they wanted to, served children } \\
\text { seconds without being asked, used food to control behaviour, sat and ate the same food with } \\
\text { the children, and consumed unhealthful foods or drinks in front of the children }\end{array}$ \\
\hline Nutrition environment & $\begin{array}{l}\text { The method(s) in which meals were served; the presence of vending machines and the nature of } \\
\text { the foods sold; visible presence of nutrition-related materials within the classrooms }\end{array}$ \\
\hline \multicolumn{2}{|l|}{ Food and beverage provision } \\
\hline Fruits and vegetables & $\begin{array}{l}\text { Frequency and types of fruits and vegetables served and on the menu; addition of added fats, } \\
\text { such as meat fat, margarine or butter }\end{array}$ \\
\hline Grains, beans and lean meat & Frequency of lean meats/fish and high-fibre grains served and on the menu \\
\hline High fat/high sugar & $\begin{array}{l}\text { Frequency of fried or pre-fried vegetables and meats served and on the menu; frequency of high- } \\
\text { fat meats served and on the menu; frequency of high-sugar and/or high-fat food and } \\
\text { condiments served and on the menu }\end{array}$ \\
\hline Beverage & $\begin{array}{l}\text { Frequency of } 100 \% \text { fruit juice served and on the menu; frequency and type of milk served and on } \\
\text { the menu; degree and type of availability and encouragement of water to the students }\end{array}$ \\
\hline Water composite & Degree and type of availability and encouragement of water to the students \\
\hline Total EPAO nutrition score & Average of the EPAO nutrition subscale item scores, excluding water composite \\
\hline
\end{tabular}


number of times high-fibre foods are included on a menu could be converted to a score of $0^{(50)}$. The scored items were grouped according to the composition of the EPAO subscales for nutrition. Subscale scores were determined by averaging the scores for the individual subscale items and multiplying by 10 , for a highest possible score of 20 per subscale. The overall EPAO nutrition scores were determined by averaging the subscale scores. Higher EPAO scores are better than lower EPAO scores, but there is no specific score or standard at which ECC become designated as 'good' or 'bad.'

We performed statistical analyses using the statistical software package IBM SPSS Statistics version 22.0. We used descriptive statistics to describe the centres' performances at baseline and follow-up. We used MannWhitney $U$ and Pearson $\chi^{2}$ tests to determine potential differences between ECC lost to follow-up $v$. those retained. For the eighteen ECC on which we had both baseline and follow-up data, we used the Wilcoxon signed-rank test to determine whether there had been statistically significant changes or not on the individual EPAO nutrition subscales and for the overall EPAO nutrition scores from baseline to follow-up. Tests were twotailed and $P$ values $<0.05$ were considered significant.

\section{Ethical considerations}

The evaluation was deemed exempt by Nova Southeastern University's Institutional Review Board.

\section{Results}

At baseline (spring 2013), we observed twenty-three ECC: thirteen ECC in the priority zip codes, four ECC in the secondary priority zip codes and six ECC in the additional zip codes. Due to ECC changing ownership, participating in reaccreditation activities or, in the case of one centre, declining to continue to participate in the evaluation activities, follow-up (spring 2014) observations involved eighteen ECC: ten ECC in the priority zip codes, three ECC in the secondary priority zip codes and five ECC in the additional zip codes. For the eighteen ECC on which we had both baseline and follow-up data, the mean number of children enrolled, staff and children per staff member at each centre was 112.9 (SD 53.4), 12.3 (SD 7.2) and 10.2 (SD 4.6), respectively (Table 3 ). Within the ECC lost to follow-up, the mean number of children enrolled, staff and children per staff member at each centre was 133.6 (SD 102.0), 14.4 (SD 13.1) and 11.7 (SD 5.1), respectively. There were no significant differences between ECC lost to follow-up and those retained in terms of baseline ECC characteristics, location within priority or additional zip codes, tier designation, total EPAO nutrition score or any EPAO nutrition subscale scores.

There was a significant improvement in the centres' total EPAO nutrition scores from a median of 11.97 to 13.34 ( $P=0.01)$. Among the EPAO nutrition subscales, ECC significantly improved their nutrition policy scores from
Table 3 Characteristics of eighteen early childcare centres (ECC) participating in evidence-based nutrition practices training, Broward County, Florida, USA, 2013-2014

\begin{tabular}{lrr}
\hline ECC characteristic & Mean & SD \\
\hline No. of children enrolled & 112.9 & 53.4 \\
No. of staff & 12.3 & 7.2 \\
No. of children per staff member & 10.2 & 4.6 \\
No. of staff with National Early Childhood Certification & 1.4 & 3.1 \\
No. of staff with college degrees or higher & 1.9 & 2.0 \\
\hline
\end{tabular}

a median of $5 \cdot 0$ to $10 \cdot 0(P=0 \cdot 03)$ and their nutrition training and education scores from a median of 8.0 to 10.0 $(P=0 \cdot 01)$. Baseline and follow-up scores were not significantly different for the subscales of fruits and vegetables; staff nutrition behaviour; high fat/high sugar; beverage; water composite; nutrition environment; and grains, beans and lean meat (Table 4). There were no significant differences in changes of total EPAO scores or EPAO nutrition subscales scores between Tier 1 and Tier 2 ECC.

\section{Discussion}

The findings from the current evaluation support the idea that training ECC directors, faculty and staff in evidencebased nutrition policies and practices, and providing technical assistance to those who need it, can help improve the nutrition contexts of ECC serving racially and ethnically diverse children from low-income households. In addition to finding significant improvements in centres' nutrition contexts, as measured by changes in their overall EPAO nutrition scores, the ECC experienced improvements within the specific EPAO nutrition subscales of nutrition policies and nutrition education for ECC staff and children. These improvements are important due to the influence ECC contexts and practices have on children's healthful decision making and eating habits ${ }^{(5,7,10,51,52)}$. This is particularly important given that the centres involved in the evaluation were located within high-need areas in terms of population-level measures of poverty, diabetes, minority representation and unhealthy food index.

The TOUCH ECC strategy focused on improving ECC nutrition policies and practices with the goal of increasing the number of children being cared for in licensed ECC that meet CFOC standards. In general, at baseline, most of the ECC had either no or weak written nutrition policies, in terms of EPAO scoring. Weak or non-existent nutrition policies within ECC are relatively commonplace ${ }^{(53,54)}$. The significant improvement in the EPAO nutrition subscale score for nutrition policy suggests that the training programme resulted in more ECC adopting more rigorous nutrition policies. ECC staff and directors were trained on the importance of establishing written nutrition policies that complied with CACFP and CFOC standards, and they were given technical assistance in problem solving 
Table 4 Environment and Policy Assessment and Observation (EPAO) nutrition scores* at baseline and follow-up among eighteen early childcare centres participating in evidence-based nutrition practices training, Broward County, Florida, USA, 2013-2014

\begin{tabular}{|c|c|c|c|c|c|}
\hline \multirow[b]{2}{*}{ EPAO nutrition subscale items } & \multicolumn{2}{|c|}{ Baseline } & \multicolumn{2}{|c|}{ Follow-up } & \multirow[b]{2}{*}{$P$ value } \\
\hline & Median & IQR & Median & IQR & \\
\hline Total EPAO nutrition score & $12 \cdot 0$ & $10 \cdot 6-13 \cdot 2$ & $13 \cdot 3$ & $12 \cdot 2-13 \cdot 8$ & 0.01 \\
\hline \multicolumn{6}{|c|}{ Nutrition policy, education and modelling } \\
\hline Nutrition policy & $5 \cdot 0$ & $0.0-10.0$ & $10 \cdot 0$ & $10 \cdot 0-15 \cdot 0$ & 0.03 \\
\hline Nutrition training and education & 8.0 & $4 \cdot 0-8.5$ & $10 \cdot 0$ & $6 \cdot 0-15 \cdot 3$ & 0.01 \\
\hline Staff nutrition behaviour & $12 \cdot 9$ & $11.4-14.8$ & $14 \cdot 3$ & $11 \cdot 4-17 \cdot 1$ & 0.32 \\
\hline Nutrition environment & $10 \cdot 0$ & $5 \cdot 0-10 \cdot 0$ & $6 \cdot 3$ & $5 \cdot 0-10 \cdot 0$ & 0.37 \\
\hline \multicolumn{6}{|l|}{ Food and beverage provision } \\
\hline Fruits and vegetables & $16 \cdot 4$ & $14 \cdot 4-18 \cdot 9$ & $17 \cdot 8$ & $16 \cdot 7-18 \cdot 9$ & 0.05 \\
\hline Grains, beans and lean meat & $15 \cdot 0$ & $13 \cdot 3-16 \cdot 7$ & 13.3 & $12 \cdot 9-16 \cdot 7$ & 0.80 \\
\hline High fat/high sugar & 12.5 & $11.4-15 \cdot 6$ & 13.0 & $15 \cdot 6-13 \cdot 3$ & 0.22 \\
\hline Beverage & $16 \cdot 7$ & $15 \cdot 4-17 \cdot 8$ & $16 \cdot 7$ & $15 \cdot 6-17 \cdot 8$ & 0.96 \\
\hline Water composite $\neq$ & $10 \cdot 0$ & $5 \cdot 0-15 \cdot 0$ & $10 \cdot 0$ & $8 \cdot 8-10 \cdot 6$ & 0.54 \\
\hline
\end{tabular}

IQR, interquartile range.

*EPAO nutrition scores range from 0 to 20 , with higher scores representing better performance.

†Wilcoxon signed-rank test comparing ordinal-level EPAO data, baseline $v$. follow-up.

$\neq$ Water composite represents the water items within the Beverage subscale.

any barriers to policy implementation. The significant improvement of centres' written nutrition policies is important because nutrition polices have demonstrated benefit in facilitating supportive feeding environments in $\mathrm{ECC}^{(12,55)}$ and improving some eating behaviours of ECC children $^{(15)}$. In addition to their benefit to ECC contexts and children, ECC-level policies have been found to positively affect ECC staff behaviour and modelling ${ }^{(51)}$. However, if ECC score well on their nutrition policy subscales but low on a number of other nutrition subscales, one could consider to what extent ECC are adopting policies but are facing barriers as they try to do so.

Interviewing ECC directors about barriers and supports to implementing nutrition policy and practice changes in ECC, Lyn et al. ${ }^{(56)}$ found that ECC could overcome barriers to providing healthier option foods once ECC directors understood which unhealthy food options could be replaced easily by healthier options. Similarly, barriers to implementing increased nutrition education for children during the day was simple enough to overcome by tweaking schedules to include nutrition activities and stories about healthful foods before eating occasions. And, the extent to which children positively respond to nutrition changes can be enhanced by the inclusion of hands-on, experiential learning related to healthful nutrition behaviours ${ }^{(56,57)}$. The primary support that the ECC directors cited as being most helpful for implementing nutrition policy and practice changes in Lyn et al.'s study was the delivery of training and technical assistance from a registered dietitian, which included providing nutrition education materials and printable resources for activities.

Parallel to the importance of nutrition policies is the value of improved nutrition education for both ECC students and staff. Nutrition education for ECC children helps the children improve their healthful, nutritional decision making and consumption $^{(12,51,52-55)}$. Nutrition education for ECC staff has potential beneficial effects due to the influence ECC staff can have on children. Sigman-Grant et al. ${ }^{(55)}$ found that CACFP-funded ECC staff who received training from nutrition professionals facilitated healthful environments within their ECC through learning, adopting and manifesting childhood obesity prevention feeding guidelines.

Although we found a significant improvement in the EPAO subscale for nutrition training and education, we did not find significant changes in the subscales of staff nutrition behaviour or nutrition environment. Lyn et al. ${ }^{(12)}$ also reported no significant change in staff nutrition behaviour in their work. They suggest that staff nutrition behaviours did not improve significantly because CACFPparticipating ECC routinely have more supportive nutrition environments due to the requirements for participation in the programme ${ }^{(12)}$. This could be at play within our evaluation, given the staff nutrition behaviour subscale median score was above the total EPAO nutrition median score at both baseline and follow-up.

Regarding the EPAO nutrition subscales associated with the provisions of healthful foods and beverages, we found no significant changes. This could be attributable to the fact that all centres participating in our evaluation relatively were performing well already in these areas, most likely due to their participation in CACFP, which includes nutritional standards as part of the programming. This differs from studies that find centres' nutrition provisions are low in fresh fruits, vegetables and whole grains $^{(12,21,58,59)}$. Nevertheless, in the ECC we observed, there is room for improvement in the provision of drinking-water to the students. In addition to the ensuring children's hydration, consuming water during the day can contribute to the prevention of weight gain among children by reducing extra energy intake $\mathrm{e}^{(36,60-63)}$.

Multicomponent policy, practice and environment obesity prevention interventions, such as the one we evaluated, have been found to be the interventions most likely to result in improved outcomes for the children 
involved, especially when focusing on children from lowincome families ${ }^{(5)}$. A number of these multicomponent interventions involve training ECC leadership and staff on nutrition, nutrition polices and nutrition practices, and providing technical assistance to ECC as they engage in nutrition policy and practice transformation. As one would imagine, there are differences in terms of significant improvements in nutrition policies, environments and practices among these more comprehensive obesity prevention interventions.

Working within ECC and using similar intervention strategies of trainings, policy and practice change and technical assistance, Lyn et al. ${ }^{(12)}$, Ward et al. ${ }^{(64)}$ and Smith et al. ${ }^{(54)}$ found significant improvements in the centres' overall nutrition contexts, but Esquivel et al. ${ }^{(65)}$ and Benjamin Neelon et al. ${ }^{(66)}$, who were working in ECC with children less than 2 years of age, did not find significant changes in overall nutrition contexts. Nevertheless, Benjamin Neelon et al. found significant improvements in the centres' provisions of high-sugar, high-salt and fatty foods and the staff nutrition behaviours within the ECC. Meanwhile, Lyn et al. found significant improvements in the nutrition environment, nutrition training and education, and nutrition policies of the ECC involved. And, Smith et al. found significant improvements in the provision of whole grains and low fats (grains, beans and lean meat), staff nutrition behaviours, nutrition environment, and nutrition training and education. Our evaluation discovered significant improvements in centres' overall nutrition contexts, nutrition policies, and the nutrition training and education of ECC staff and children, but it did not find significant improvements in the nutrition behaviours of staff, the nutrition environments of the ECC classrooms, or the provisions of foods and beverages.

The differences and similarities among the published studies reflect the contextual nature of working within centres' nutrition milieu. The extent to which centres do or do not share similar contexts and needs influences the extent to which various policy and practice interventions do or do not address their needs. Additionally, interventions might improve particular aspects of centres' policies, environments and practices, but they might not improve others. This was evident within our evaluation.

While one could suggest that some of the changes experienced by the ECC within our study were relatively small, even small improvements in particular policies, practices and environments improve the overall nutrition contexts of the centres and encourage healthy nutrition behaviours ${ }^{(13)}$. Additionally, because of the unique population served by the intervention we evaluated and given the short, one-year time frame of our evaluation, our findings reveal the positive outcomes of participating centres' initial efforts and show promise for what these efforts might lead to as practice change occurs over time.

Despite our efforts in planning and executing an evaluation that maintained rigour in the face of practical, in-the-field challenges, the present study does have limitations. Although there were practical reasons preventing us from utilizing a comparison group of ECC, doing so would have provided more robust conclusions about the role of the intervention on changes in centres' nutrition policies, environments, food and beverage provision, and student and staff behaviours. Future evaluations should strive to include a comparison group to enhance the certainty on the extent to which observed effects are attributable to the intervention. Additionally, the relatively small sample size for the evaluation calls for caution when seeking to generalize the findings to other settings. Nevertheless, our evaluation did utilize a validated instrument, approved and recommended for use by the CDC for Community Transformation Grant evaluators, and our findings provided useful, valid feedback to the community partners involved in TOUCH.

\section{Conclusion}

Our evaluation suggests that training ECC directors, faculty and staff in evidence-based nutrition strategies can help improve the nutrition policies and nutrition education practices of ECC serving children in high-need areas. It is commonly accepted that policy can play an important role in fostering the health contexts of institutional education settings $^{(7,14,52)}$. However, in our setting, the intervention resulted in improvements to some nutrition policies and practices, but it did not do so for others. Clearly, there remains a need to further develop the evaluation base involving the effectiveness of policy and practice interventions within ECC serving 2-5-year-olds ${ }^{(5,14)}$.

Until fairly recently, the most common places for policy interventions seeking to improve nutrition contexts and practices have occurred in elementary- and middle-school settings ${ }^{(5,14)}$. As such, our findings are valuable given: (i) the need for studies that focus on policy-level interventions incorporating evidence-based guidelines and practices $^{(7)}$ in institutional settings, such as $\mathrm{ECC}^{(30)}$; (ii) our study's unique involvement with ECC serving racially and ethnically diverse children located within areas of high rates of poverty, diabetes, minority representation and unhealthy food index; and (iii) the understanding that ECC and their nutrition contexts are essential public health arenas for preventing and addressing childhood obesity, including the disparities that persist in children of preschool age across racial, ethnic and income groups ${ }^{(1,2)}$.

\section{Acknowledgements}

Acknowledgements: The authors acknowledge and warmly thank Monica Pujol-Nassif from Family Central, Inc.; the directors, staff and children of the ECC that participated in our evaluation; the Nova Southeastern University MPH students who assisted in data collection 
for our evaluation; and Dr Janice Vick, Dr Kathleen Whitten and Donoria Evans from ICF International for their guidance and support in manuscript development. They are particularly grateful for the help of Marlene Colon from United Way of Miami-Dade, formerly from Family Central, Inc., in serving as a liaison and scheduler between our evaluation team and the ECC. Financial support: This paper was supported in part by a cooperative agreement with the CDC (grant number \#U58DP003661). Portions of this project's work involve the Communities Transforming initiative supported by CDC funding. However, the findings and conclusions in this paper are those of the authors and do not necessarily represent the official position of the CDC. Users of this document should be aware that every funding source has different requirements governing the appropriate use of those funds. Under US law, no federal funds are permitted to be used for lobbying or to influence, directly or indirectly, specific pieces of pending or proposed legislation at the federal, state or local levels. Organizations should consult appropriate legal counsel to ensure compliance with all rules, regulations and restriction of any funding sources. Conflict of interest: The authors declare that they have no conflicts of interest. Authorship: T.L.H. was the primary author of the manuscript, led the design of the evaluation, analysed the data and led data collection efforts. N.C. assisted in writing the manuscript, assisted in the design of the evaluation, assisted with data collection and reviewed drafts of the manuscript. R.N. led the writing of the 'Intervention' subsection of the 'Methods' section and reviewed drafts of the manuscript. D.Q. led data management, led data entry, assisted with data collection and reviewed drafts of the manuscript. T.P. led project development, assisted with the writing of the 'Intervention subsection' of the 'Methods' and reviewed drafts of the manuscript. M.D. led project conceptualization and development and reviewed drafts of the manuscript. Ethics of buman subject participation: This evaluation did not involve human subjects.

\section{References}

1. Ogden CL, Carroll MD, Kit BK et al. (2014) Prevalence of childhood and adult obesity in the United States, 2011-2012. $J$ Am Med Assoc 311, 806-814.

2. Centers for Disease Control and Prevention, Division of Nutrition, Physical Activity, and Obesity (2017) Prevalence of Childhood Obesity in the United States, 2011-2014. Childhood Obesity Facts. https://www.cdc.gov/obesity/ data/childhood.html (accessed November 2017).

3. Skinner AC, Perrin EM \& Skelton JA (2016) Prevalence of obesity and severe obesity in US children, 1999-2014. Obesity (Silver Spring) 24, 1116-1123.

4. Centers for Disease Control and Prevention, National Center for Health Statistics (2017) Table 59: Obesity among children and adolescents aged 2-19 years, by selected characteristics: United States, selected years 1988-1994 through 2011-2014. Health, United States, 2016: With Chartbook on Long-term Trends in Health. https://www.cdc.gov/nchs/data/hus/2016/ 059.pdf (accessed November 2017).
5. Mikkelsen MV, Husby S, Skov LR et al. (2014) A systematic review of types of healthy eating interventions in preschools. Nutr J 13, 56-74.

6. Hollar D, Lombardo M, Lopez-Mitnik G et al. (2010) Effective multi-level, multi-sector, school-based obesity prevention programming improves weight, blood pressure, and academic performance, especially among low-income, minority children. J Health Care Poor Underserved 21, Suppl. 2, S93-S108.

7. Larson N, Ward DS, Neelon SB et al. (2011) What role can child-care settings play in obesity prevention? A review of the evidence and call for research efforts. J Am Diet Assoc 111, 1343-1362.

8. Natale R, Scott SH, Messiah SE et al. (2013) Design and methods for evaluating an early childhood obesity prevention program in the childcare center setting. BMC Public Health 28, 78-87.

9. Hollar D, Messiah SE, Lopez-Mitnik G et al. (2010) Effect of a two-year obesity prevention intervention on percentile changes in body mass index and academic performance in low-income elementary school children. Am J Public Health 100, 646-653

10. Erinosho TO, Beth Dixon L, Young C et al. (2013) Caregiver food behaviors are associated with dietary intakes of children outside the child-care setting. Public Health Nutr 16, 1263-1272.

11. Kaphingst KM \& Story M (2009) Child care as an untapped setting for obesity prevention: state child care licensing regulations related to nutrition, physical activity, and media use for preschool-aged children in the United States. Prev Chronic Dis 6, A11.

12. Lyn R, Maalouf J, Evers S et al. (2013) Nutrition and physical activity in child care centers: the impact of a wellness policy initiative on environment and policy assessment and observation outcomes, 2011. Prev Chronic Dis 23, E83.

13. Battista RA, Oakley H, Weddell MS et al. (2014) Improving the physical activity and nutrition environment through selfassessment (NAP SACC) in rural area child care centers in North Carolina. Prev Med 67, Suppl. 1, S10-S16.

14. Lessard L, Lesesne C, Kakietek J et al. (2014) Measurement of compliance with New York City's regulations on beverages, physical activity, and screen time in early child care centers. Prev Chronic Dis 16, E183.

15. Kakietek J, Osuji TA, O'Dell SA et al. (2014) Compliance with New York City's beverage regulations and beverage consumption among children in early child care centers. Prev Chronic Dis 16, E180.

16. US Department of Health and Human Services (2010) The Surgeon General's Vision for a Healthy and Fit Nation. Rockville, MD: US Department of Health and Human Services, Office of the Surgeon General; available at http:// www.surgeongeneral.gov/priorities/healthy-fit-nation/ obesityvision2010.pdf

17. White House Task Force on Childhood Obesity (2010) Solving the Problem of Childhood Obesity within a Generation: White House Task Force on Childhood Obesity Report to the President. http://www.letsmove.gov/sites/ letsmove.gov/files/TaskForce_on_Childhood_Obesity_May 2010_FullReport.pdf (accessed August 2015).

18. Laughlin L (2013) Who's Minding the Kids? Child Care Arrangements: Spring 2011. Current Population Reports P70-135. Washington, DC: US Census Bureau.

19. US Department of Education, Institute of Education Sciences, National Center for Education Statistics (2014) Table 202.40 - Child care arrangements of 3- to 5-yearold children who are not yet in kindergarten, by age and race/ethnicity: Selected years, 1991 through 2012. Digest of Education Statistics 2013. http://www.nces.ed. gov/programs/digest/d14/tables/dt14_202.40.asp?current=yes (accessed August 2015). 
20. Treviño RP, Vasquez L, Shaw-Ridley M et al. (2015) Outcome of a food observational study among low-income preschool children participating in a family-style meal setting. Health Educ Behav 42, 240-248.

21. Ball SC, Benjamin SE \& Ward DS (2008) Dietary intakes in North Carolina child-care centers: are children meeting current recommendations? J Am Diet Assoc 108, 718-721.

22. Centers for Disease Control and Prevention, Division of Nutrition, Physical Activity, and Obesity (2015) Early Care and Education (ECE). Strategies to Prevent Obesity. http:// www.cdc.gov/obesity/strategies/childcareece.html (accessed August 2015).

23. Davis M, Gance-Cleveland B, Hassink S et al. (2007) Recommendations for prevention of childhood obesity. Pediatrics 120, Suppl. 4, S229-S253.

24. Chandler I, Rosenthal L, Carroll-Scott A et al. (2015) Adolescents who visit the emergency department are more likely to make unhealthy dietary choices: an opportunity for behavioral intervention. J Health Care Poor Underserved 26, 701-711.

25. Carlson JA, Crespo NC, Sallis JF et al. (2012) Dietary-related and physical activity-related predictors of obesity in children: a 2-year prospective study. Child Obes 8, 110-115.

26. Ludwig D, Peterson K \& Gortmaker S (2001) Relation between consumption of sugar-sweetened drinks and childhood obesity: a prospective, observational analysis. Lancet 357, 505-508.

27. Institute of Medicine/National Academy of Medicine (2011) Child and Adult Care Food Program: Aligning Dietary Guidance for All. Washington, DC: The National Academies Press; available at http://www.nap.edu/read/12959/chap ter/3

28. Zhang D, Li Z, Wang $\mathrm{H}$ et al. (2015) Interactions between obesity-related copy number variants and dietary behaviors in childhood obesity. Nutrients 7, 3054-3066.

29. Hoelscher DM, Kirk S, Ritchie L et al. (2013) Position of the Academy of Nutrition and Dietetics: interventions for the prevention and treatment of pediatric overweight and obesity. J Acad Nutr Diet 113, 1375-1394.

30. Wang Y, Cai L, Wu Y et al. (2015) What childhood obesity prevention programmes work? A systematic review and meta-analysis. Obes Rev 16, 547-565.

31. Wang Y, Wu Y, Wilson RF et al. (2013) Childhood Obesity Prevention Programs: Comparative Effectiveness Review and Meta-Analysis. Rockville, MD: Agency for Healthcare Research and Quality.

32. Kumanyika SK, Swank M, Stachecki J et al. (2014) Examining the evidence for policy and environmental strategies to prevent childhood obesity in black communities: new directions and next steps. Obes Rev 15, Suppl. 4, 177-203.

33. Department of Health and Human Services (2013) Community Transformation Grants (CTG). Atlanta, GA: US Department of Health and Human Services, Centers for Disease Control and Prevention, National Center for Chronic Disease Prevention and Health Promotion, Division of Community Health; available at http://www.cdc.gov/ nccdphp/dch/programs/communitytransformation/index.htm

34. Patient Protection and Affordable Care Act (2010) US Public Law 111-148, 111th Congress, Sec 4201, March 23, 2010. http://www.gpo.gov/fdsys/pkg/PLAW-111publ148/pdf/PLAW111publ148.pdf (accessed January 2016).

35. Broward Regional Health Planning Council (2014) About TOUCH: Transforming Our Community's Health. http:// www.touchbroward.org/about/ (accessed October 2014).

36. American Academy of Pediatrics, American Public Health Association \& National Resource Center for Health and Safety in Child Care and Early Education (2011) Caring for Our Children: National Health and Safety Performance Standards; Guidelines for Early Care and Education Programs, 3rd ed. Elk Grove Village, IL/Washington, DC:
American Academy of Pediatrics/American Public Health Association; available at http://www.nrckids.org

37. Natale R, Camejo S \& Sanders L (2016) Communities putting prevention to work: results of an obesity prevention initiative in child care facilities. J Res Child Educ 30, 306-319.

38. Natale R, Messiah S, Asfour L et al. (2017) Obesity prevention program in childcare centers: two-year follow-up. $A m J$ Health Promot 31, 502-510.

39. US Department of Health and Human Services \& US Department of Agriculture (2015) 2015-2020 Dietary Guidelines for Americans, 8th ed. Washington, DC: US Government Printing Office; available at http://www.health. gov/dietaryguidelines/2015/guidelines/

40. US Department of Agriculture, Food and Nutrition Service (2017) Child and Adult Care Food Program: Nutrition Standards for CACFP Meals and Snacks. http://www.fns.usda. gov/cacfp/meals-and-snacks (accessed September 2017).

41. Natale RA, Lopez-Mitnik G, Uhlhorn SB et al. (2014) Effect of a child care center-based obesity prevention program on body mass index and nutrition practices among preschoolaged children. Health Promot Pract 15, 695-705.

42. Natale R, Messiah S, Asfour L et al. (2014) Role modeling as an early childhood obesity prevention strategy: effect of parents and teachers on preschool children's healthy lifestyle habits. J Dev Behav Pediatr 35, 378-387.

43. Transforming Our Community's Health (2014) Resource Manual Nutrition and Physical Activity in Early Childhood Education. Hollywood, FL: Broward Regional Health Planning Council; available at http://www.touchbroward.org/ resources/early-learning-resources-for-childcare-facilities-andparents/

44. Team Nutrition, Child Nutrition Division (2013) Nutrition and Wellness Tips for Young Children: Provider Handbook for the Child and Adult Care Food Program. Alexandria, VA: US Department of Agriculture, Food and Nutrition Service; available at http://www.fns.usda.gov/tn/nutritionwellness-tips-young-children

45. US Department of Agriculture, Center for Nutrition Policy and Promotion (2011/2016) 10 Tips Nutrition Education Series. Alexandria, VA: US Department of Agriculture, Center for Nutrition Policy and Promotion; available at http:// www.choosemyplate.gov/node/1924

46. Florida Department of Health, Bureau of Child Care Food Programs (2008) A Dozen Ways to Be Healthy. Tallahassee, FL: Florida Department of Health; available at http://www. floridahealth.gov/programs-and-services/childrens-health/childcare-food-program/nutrition/preschool-lesson-plans.html

47. Share our Strength's Cooking Matters: No Kid Hungry (2017) Exploring Food Together. Washington, DC: Share our Strength; available at http://www.cookingmatters.org/ educational-tools

48. Ward DS, Hales DP, Haverly K et al. (2008) An instrument to assess the obesogenic environment of child care centers. Am J Health Behav 32, 380-386.

49. Benjamin SE, Neelon B, Ball SC et al. (2007) Reliability and validity of a nutrition and physical activity environmental selfassessment for child care. Int J Behav Nutr Phys Act 4, 29-39.

50. Bower JK, Hales DP, Tate DF et al. (2008) The childcare environment and children's physical activity. Am J Prev Med 34, 23-29.

51. Erinosho TO, Hales DP, McWilliams CP et al. (2012) Nutrition policies at child-care centers and impact on role modeling of healthy eating behaviors of caregivers. J Acad Nutr Diet 112, 119-124.

52. Story M, Kaphingst KM \& French S (2006) The role of child care settings in obesity prevention. Future Child 16, 143-168.

53. Gerritsen S, Wall C \& Morton S (2016) Child-care nutrition environments: results from a survey of policy and practice in New Zealand early childhood education services. Public Health Nutr 19, 1531-1542. 
54. Smith TM, Blaser C, Geno Rasmussen C et al. (2017) Assessment of nutrition and physical activity practices using self-report and observation in early care and education across multiple US states. Public Health Nutr 20, 1692-1698.

55. Sigman-Grant M, Christiansen E, Fernandez G et al. (2011) Child care provider training and a supportive feeding environment in child care settings in 4 states, 2003. Prev Chronic Dis 8, A113.

56. Lyn R, Evers S, Davis J et al. (2014) Barriers and supports to implementing a nutrition and physical activity intervention in child care: directors' perspectives. J Nutr Educ Behav $\mathbf{4 6}$, 171-180.

57. Cooke L (2007) The importance of exposure for healthy eating in childhood: a review. J Hum Nutr Diet 20, 294-301.

58. Freedman MR \& Alvarez KP (2010) Early childhood feeding: assessing knowledge, attitude, and practices of multi-ethnic child-care providers. J Am Diet Assoc 110, 447-451.

59. Padget A \& Briley ME (2005) Dietary intakes at childcare centers in central Texas fail to meet Food Guide Pyramid recommendations. I Am Diet Assoc 105, 790-793.

60. Kleinman RE (editor) (2009) Pediatric Nutrition Handbook, 6th ed. Elk Grove Village, IL: American Academy of Pediatrics.

61. Nonas C, Silver LD, Khan L et al. (2014) Rationale for New York city's regulations on nutrition, physical activity, and screen time in early child care centers. Prev Chronic Dis 16, E182.

62. Daniels MC \& Popkin BM (2010) Impact of water intake on energy intake and weight, status: a systematic review. Nutr Rev 68, 505-521.

63. Muckelbauer R, Libuda L, Clausen K et al. (2009) Promotion and provision of drinking water in schools for overweight prevention: randomized, controlled cluster trial. Pediatrics 123, e661-e667.
64. Ward DS, Benjamin SE, Ammerman AS et al. (2008) Nutrition and physical activity in child care: results from an environmental intervention. Am J Prev Med 35, 352-356.

65. Esquivel MK, Nigg CR, Fialkowski MK et al. (2016) Influence of teachers' personal health behaviors on operationalizing obesity prevention policy in Head Start preschools: a project of the Children's Healthy Living Program (CHL). J Nutr Educ Behav 48, 318-325.

66. Benjamin Neelon SE, Taveras EM, Ostbye T et al. (2014) Preventing obesity in infants and toddlers in child care: results from a pilot randomized controlled trial. Matern Child Health J 18, 1246-1257.

\section{Appendix}

- A copy of the original Environment and Policy Assessment and Observation protocol can be found at: http://www.centertrt.org/content/docs/Intervention_ Documents/Intervention_Materials/NAP_SACC/Evaluation_ Materials/Environment_Policy_Assessment_and_Observa tion_EPAO_Instrument.pdf

- A copy of the Transforming Our Community's Health Resource Manual Nutrition and Physical Activity in Early Childbood Education can be found at: http://www. touchbroward.org/resources/early-learning-resourcesfor-childcare-facilities-and-parents/ 